\title{
Preparation of activated carbon from oil palm empty fruit bunch (EFB) by steam activation using response surface methodology
}

\author{
Sharifah Aishah Syed A. Kadir, Sharmeela Matali, Nor Fadilah Mohamad, \\ Noor Hidayu Abdul Rani*
}

Faculty of Chemical Engineering, Universiti Teknologi MARA, Shah Alam, Selangor, Malaysia

Email address:

hidayu_rani@yahoo.com (N. H. A. Rani)

\section{To cite this article:}

Sharifah Aishah Syed A. Kadir, Sharmeela Matali, Nor Fadilah Mohamad, Noor Hidayu Abdul Rani. Preparation of Activated Carbon from Oil Palm Empty Fruit Bunch (EFB) by Steam Activation Using Response Surface Methodology. International Journal of Materials Science and Applications. Vol. 3, No. 5, 2014, pp. 159-163. doi: 10.11648/j.jimsa.20140305.15

\begin{abstract}
This paper aims to find the optimum conditions for preparation of activated carbon from empty fruit bunch (EFB) using physical steam activation by applying response surface methodology (RSM) with maximizing the BET surface area. The main process variables for this study were activation temperature and activation time and quadratic model was developed for a BET surface area which was selected as the investigated response. According to the RSM tool, the optimum conditions that were obtained from this study are at an activation temperature of $764.5^{\circ} \mathrm{C}$ and activation time of $77 \mathrm{~min}$ which give the maximum of BET surface area; $717.6 \mathrm{~m}^{2} / \mathrm{g}$. Based on this optimum condition, the experimental value of BET surface area is $720.0 \mathrm{~m}^{2} / \mathrm{g}$ and is found to agree adequately with that $\left(717.6 \mathrm{~m}^{2} / \mathrm{g}\right)$ predicted from the model.
\end{abstract}

Keywords: Oil Palm Empty Fruit Bunches, Steam Activation, Activated Carbon, Response Surface Methodology, BET Surface Area

\section{Introduction}

Activated carbon is widely used known as the most effective and useful adsorbents for the removal of pollutants from polluted gas and liquid because activated carbons have a large active surface area which can provide high adsorption capacity, well developed porous structures and good mechanical properties [1, 2]. Generally, activated carbons are produced by two-stage processes which are carbonization and followed by activation at high temperature either physically or chemically to produce an amorphous material with high surface area [3]. In physical activation process, the char that obtained from carbonization was activated with oxidizing gases such as steam or carbon dioxide at high temperature whereas for chemical activation process the starting materials are impregnated with a dehydrating agent [4].

Currently, researches interests are intensifying in the use of renewable source, low-cost and abdundant lignocellulosic material as the common feedstock for the production of activated carbons [5]. In Malaysia, one of the promising agricltural wastes to be utilized as an activated carbon is oil palm empty fruit bunch (EFB) because it is abundantly available in Malaysia and has very low high market value [6].

From previous researches, the activated carbons not only dependent on physio-chemical properties of starting materials but also dependent on the method preparation conditions which are suitable for certain applications [5]. In consideration of the treatment effects on characteristics of the manufacturing activated carbon, response surface methodology (RSM) has been applied as an experimental design in discovering the finest operating conditions. RSM is a very effective technique for this study because it presents statistical models which can be used to know the relationship between the parameters that have been optimized [2].

RSM was originally developed by Box and Wilson (1951) and has been found to be a useful tool to analyses the interactions of two or more variables [1]. RSM is useful for designing experiment, creating models, evaluating the effects of several variables and identifying the optimum conditions for desirable responses and helpful in reducing the number of experiments [7]. Though RSM is a popular 
tool in process optimization, its application in EFB activated carbon production is has not been studied extensively for two operating variables. Some of the previous studies found, RSM is applied in preparation of activated carbons from precursors such as biochar, olive-waste cakes, Luscar char and Turkish lignite with three process variables $[5,8]$.

Hence, the goal of this study is to utilize oil palm EFB for the production of activated carbon by steam activation and the application of RSM to identify the optimum preparation conditions for activated carbon with two operating variables, which gave the highest BET surface area. By considering the activation time and activation temperature as operating variables, a regression model for surface area (response) was developed.

\section{Material and Methods}

\subsection{Raw Material}

Empty fruit bunches (EFB) were collected from a palm oil producer (Meru Palm Oil Mill Sdn Bhd) in Klang, Selangor. The materials were cleaned with distilled water several times to remove dust and impurities.

\subsection{Activated Carbon Preparation}

The dried EFB $(300 \mathrm{~g})$ was carbonized at $500^{\circ} \mathrm{C}$ for $1 \mathrm{~h}$ in a turbular furnace, which consists of a vertical stainless steel reactor of length $35 \mathrm{~cm}$ and internal diameter of $9 \mathrm{~cm}$ in order to produce char. Then, the EFB chair was activated by injection of steam at flow rate $120 \mathrm{ml} / \mathrm{hr}$ at desired activation temperature and activation time. The experimental variables were activation temperature between the range of $750^{\circ} \mathrm{C}$ to $800^{\circ} \mathrm{C}$ and activation time of steam of range $60 \mathrm{~min}$ to 120 min. The activated carbon that was produced quantitative estimates for the BET surface area. AUTOSORB-1 (Quanta Chrome Instruments) was used in order to determine the BET surface area. The schematic diagram of experimental set-up for physical activation process is as shown in Fig. 1.

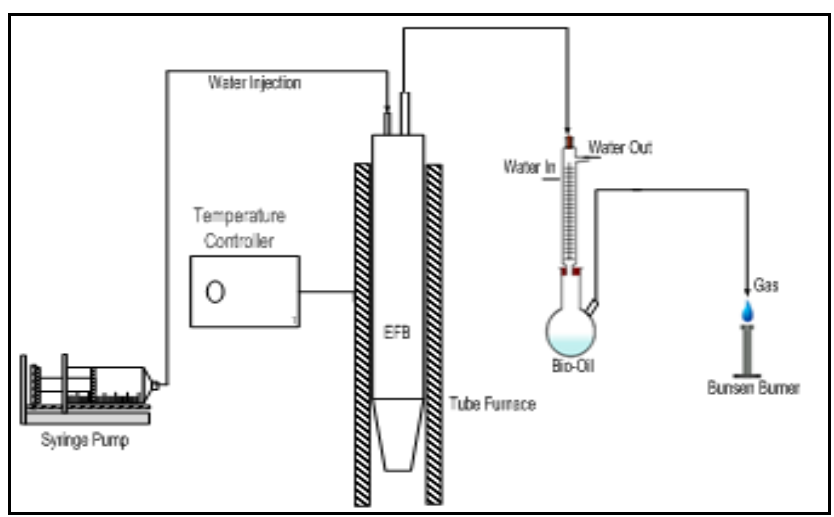

Figure 1. Experimental Set-up in Preparation of Activated Carbon

\subsection{Response Surface Methodology}

Central composite design (CCD) was applied to investigate a combine effect of several variables and to find the optimum conditions for activated carbon production [7]. Activation temperature $\left(\mathrm{A},{ }^{\circ} \mathrm{C}\right)$ and activation time $(\mathrm{B}, \mathrm{min})$ were chosen as operating variables. BET surface area $(\mathrm{Y}$, $\mathrm{m}^{2} / \mathrm{g}$ ) was used as a response. The range and levels of the operating variables studied were selected are shown in Table 1. The value of $\alpha$ for this CCD was fixed at 1.414 .

Table 1. High and low level of factors

\begin{tabular}{lllllll}
\hline Variables & Symbol & $\boldsymbol{- \alpha}$ & $\mathbf{- 1}$ & $\mathbf{0}$ & $+\mathbf{1}$ & $+\boldsymbol{\alpha}$ \\
\hline Temperature $\left({ }^{\circ} \mathrm{C}\right)$ & $\mathrm{A}$ & 739.65 & 750 & 775 & 800 & 810.36 \\
Time $(\mathrm{min})$ & $\mathrm{B}$ & 48 & 60 & 90 & 120 & 132 \\
\hline
\end{tabular}

A full factorial CCD for the two variables, consisting of 5 factorial points, 4 axial points and 4 replicates at the center points are employed, with a total of 13 experiments were required, as calculated from the equation below.

$$
\mathrm{N}=2^{\mathrm{n}}+2 \mathrm{n}+\mathrm{n}_{\mathrm{c}}=2^{2}+2(2)+5=13
$$

Where ' $\mathrm{N}$ ' is the total of experiments, while ' $\mathrm{n}$ ' is the number of independent variables.

The complete design matrix of the 13 experiments with the result obtained were performed in Table 2. The statistical software Design Expert 8.0.7.1 (STAT-EASE Inc., Minneapolis, USA) was used to analyse the data of the experimental design, analysis of variance (ANOVA) and regression analysis to fit the equations developed. The second order polynomial model was fitted for BET surface area obtained. Three-dimensional plots and their respective contour plots were obtained to study the interaction of one variable with another and the optimum conditions for preparation of activated carbon was identified.

Table 2. Experimental design matrix and results

\begin{tabular}{lllll}
\hline $\begin{array}{l}\text { Standard } \\
\text { no. }\end{array}$ & $\begin{array}{l}\text { Run } \\
\text { no. }\end{array}$ & $\begin{array}{l}\text { Temperature } \\
\left({ }^{\mathbf{0}} \mathbf{C}\right)\end{array}$ & $\begin{array}{l}\text { Activation time } \\
(\mathbf{m i n})\end{array}$ & $\begin{array}{l}\text { BET surface } \\
\text { area }\left(\mathbf{g} / \mathbf{m}^{\mathbf{2}}\right)\end{array}$ \\
\hline 1 & 9 & 750 & 60 & 693.6 \\
2 & 10 & 800 & 60 & 246.5 \\
3 & 7 & 750 & 120 & 266.5 \\
4 & 13 & 800 & 120 & 482.6 \\
5 & 12 & 739.64 & 90 & 459.1 \\
6 & 2 & 810.35 & 90 & 316.3 \\
7 & 11 & 775 & 48 & 484.6 \\
8 & 1 & 775 & 132 & 360.7 \\
9 & 5 & 775 & 90 & 640.2 \\
10 & 8 & 775 & 90 & 665.0 \\
11 & 3 & 775 & 90 & 729.3 \\
12 & 4 & 775 & 90 & 725.4 \\
13 & 6 & 775 & 90 & 721.3 \\
\hline
\end{tabular}

\section{Result and Discussions}

\subsection{Development of Regression Model Equation}

The value BET surface area that was obtained from experiments was found to range from $246.5 \mathrm{~m}^{2} / \mathrm{g}$ to 729.3 $\mathrm{m}^{2} / \mathrm{g}$ as shown as in Table 2. Based on the sequential model sum of squares, the highest order polynomials were used for 
choosing the model, where the additional terms was significant and the model was not aliased [8]. As recommended by the software, quadratic model was selected for BET surface area. Eq. (1) represents the regression model for response (BET) in terms of actual units.

Table 3. Analysis of variance (ANOVA) for selected model for BET surface area

\begin{tabular}{|c|c|c|c|c|c|c|}
\hline Source & Sum of squares & DF & Mean Square & F Value & Prob $>$ F & Status \\
\hline Model & 396937.514 & 5 & 79387.503 & 74.986 & $<0.0001$ & Significant \\
\hline A & 23430.68 & 1 & 23430.68 & 22.132 & 0.0022 & \\
\hline B & 16764.733 & 1 & 16764.733 & 15.835 & 0.0053 & \\
\hline $\mathrm{AB}$ & 109958.56 & 1 & 109958.56 & 103.863 & $<0.0001$ & \\
\hline $\mathrm{A}^{2}$ & 156498.262 & 1 & 156498.262 & 147.822 & $<0.0001$ & \\
\hline $\mathrm{B}^{2}$ & 122155.784 & 1 & 122155.784 & 115.383 & $<0.0001$ & \\
\hline Residual & 7410.835 & 7 & 1058.691 & & & \\
\hline Lack of Fit & 723.143 & 3 & 241.048 & 0.144 & 0.9283 & Not significant \\
\hline Pure Error & 6687.692 & 4 & 1671.923 & & & \\
\hline Cor Total & 404348.349 & 12 & & & & \\
\hline $\mathrm{R}^{2}$ & 0.982 & & & & & \\
\hline Adj. $R^{2}$ & 0.969 & & & & & \\
\hline Pred. $\mathrm{R}^{2}$ & 0.961 & & & & & \\
\hline Std dev. & 32.54 & & & & & \\
\hline
\end{tabular}

A: activation temperature $\left({ }^{\circ} \mathrm{C}\right), \mathrm{B}$ : activation time (min)

$\mathrm{BET}=696.24-54.12 \mathrm{~A}-45.78 \mathrm{~B}+165.80 \mathrm{AB}-149.99 \mathrm{~A}^{2}-132.51 \mathrm{~B}^{2}$

where $\mathrm{A}$ is activation temperature $\left({ }^{\circ} \mathrm{C}\right), \mathrm{B}$ is activation time in minute ( $\mathrm{min}$ ) and BET surface area in $\mathrm{m}^{2} / \mathrm{g}$, respectively. Positive sign in front of the terms $\mathrm{AB}$ indicates synergistic effect on BET surface area whereas negative signs of coefficients for $\mathrm{A}, \mathrm{B}, \mathrm{A}^{2}$ and $\mathrm{B}^{2}$ terms indicates antagonistic effects. The analysis of variance (ANOVA) is summarized in Table 3.

\subsection{Statistical Model Analysis}

The results show that the model predicted for the BET surface area was sufficient. The regression model obtained was significant $(\mathrm{P}<0.05)$ with $\mathrm{R}^{2}$ value of 0.982 and adjusted $R^{2}$ was 0.969 . The closer the $R^{2}$ value to unity, the model will be of better quality and will give predicted values closer to the actual values for the response [9]. For predicted $\mathrm{R}^{2}$, the value was 0.962 and is in reasonable agreement with the adjusted $\mathrm{R}^{2}$. It demonstrates a satisfactory agreement between experimental and predicted values as the lack of fit F-value was insignificant for the model.

Analysis of variance (ANOVA) was further studied to justify the adequacy of model. The ANOVA is a sign whether the regression equation adequately represents the relationship between the response and significant variables [9]. The results of the ANOVA for the quadratic model of BET surface area activated carbon is also listed in Table 3. The Model F-value of 74.99 and Prob $>$ F of $<0.0001$ implied that the developed model was significant. Values of "Prob > F" less than 0.05 indicated that the model terms were significant and if the values of "Prob $>$ F" greater than 0.1 indicated the model terms were not significant. In this study, activation temperature (A), activation time (B), $\mathrm{A}^{2}, \mathrm{~B}^{2}$ and $\mathrm{AB}$ were significant model terms to response, $\mathrm{BET}$ surface area.

Fig. 2 shows the predicted values against the experimental values for BET surface area and from this figure it can be seen that these values were significantly close to each other. This indicates that the developed model was successful in capturing the correlation between the activated carbon preparation of chosen variables to BET surface area.

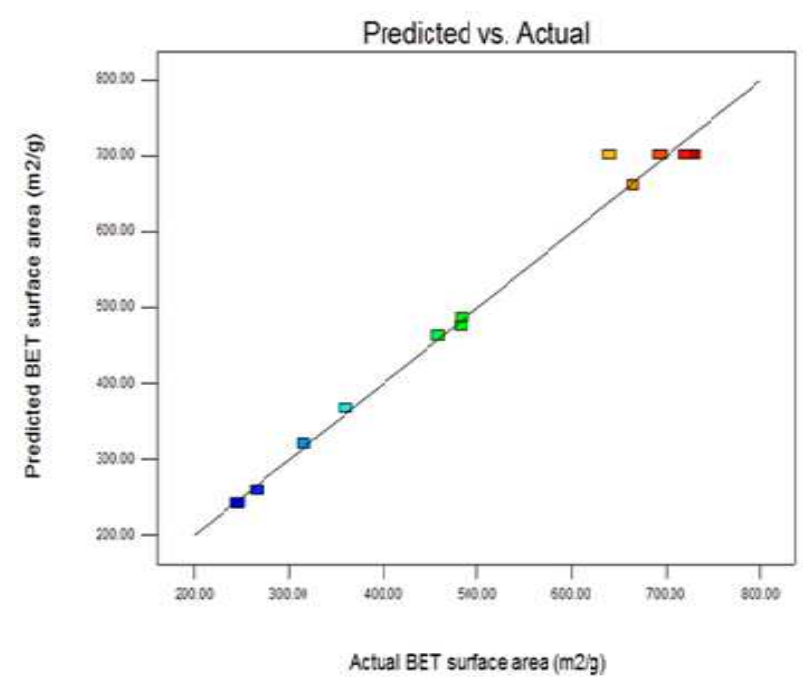

Figure 2. Predicted vs Experimental BET Surface Area.

\subsection{Effect of Operating Variables on the BET Surface Area}

Based on the ANOVA, the effects of two operating variables on the BET surface area of EFB activated carbon were investigated by using RSM three dimensional plots and contour plots. Fig. 3 and Fig. 4 show the response surface and contour plots for BET surface area with respect to physical activation temperature and activation time. Initially, the BET surface area increases with an increase in the activation temperature. This is because at high temperature, low-molecular weight volatiles were released 
from the matrix structure and generated the fragile structure, resulting pore size increased [10]. However, as time breakdown occurred, BET surface area slowly decreased because the reaction was too extreme, so the micropores would have coalesced, resulting in mesopores [11]. According to Allwar, this may be caused by the excessive heat treatment and resulted the walls of porosities were broken and closed the mouth of pores [12]. The result obtained is agreement with research study reported by Alam et al., (2008) that at high temperature, excessive heat transfer may cause shrinkage of activated carbon, resulting in narrowing or closing pores [13].

At long time activation, BET surface area was increased. This may due at long time, the development of porosity was higher than a short time because steam was penetrated deeper inside of particles $[11,14]$. However, when duration was too long, BET surface area was decreased. This may be due to the excessive carbon content burn-off which indirectly affects the quality of EFB activated carbon [1]. In addition, as the high activation temperature has to be maintained for a longer period of time, this will result on higher energy cost will be acquired.

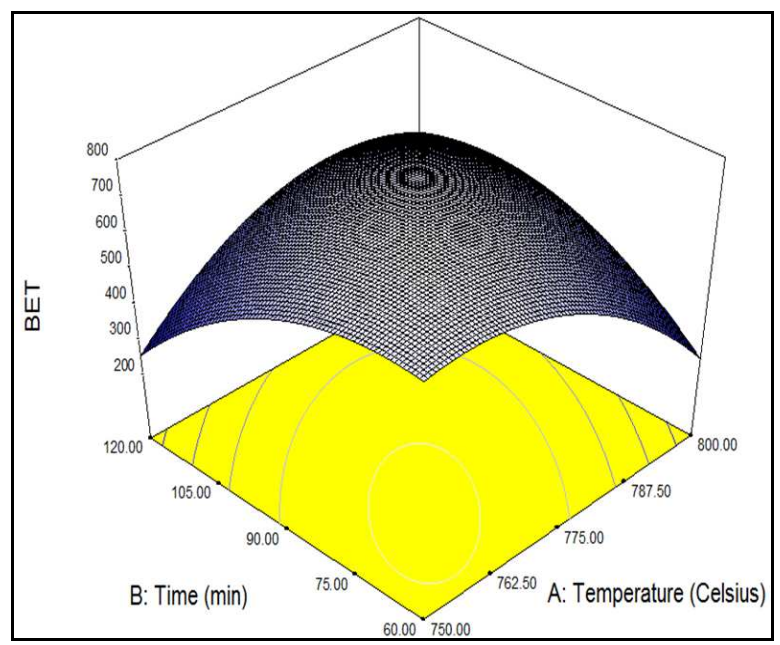

Figure 3. Response surface plot

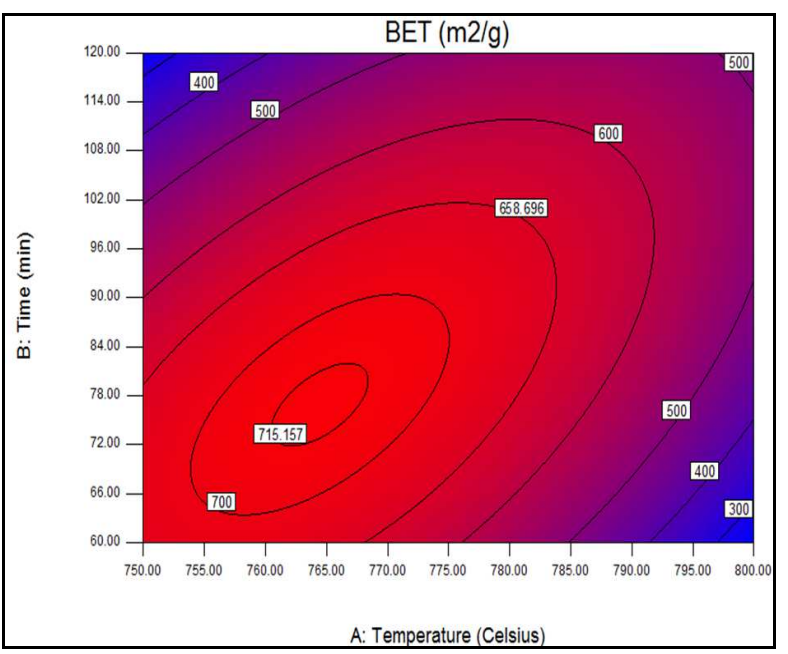

Figure 4. Contour plot showing the effects of activation temperature and activation time on BET surface area

\subsection{Process Optimization}

Optimization of the activation variables was identified using the optimizer function in the Design Expert software. The results are tabulated in Table 4 . The optimum operating conditions calculated, physical steam activation temperature of $764.5^{\circ} \mathrm{C}$ and activation time of $77 \mathrm{~min}$. Under the optimum activation conditions, BET surface area of EFB activated carbon that was predicted by the model and experimental are $717.6 \mathrm{~m}^{2} / \mathrm{g}$ and $720.0 \mathrm{~m}^{2} / \mathrm{g}$, respectively. The optimum conditions of experimental and predicted results showed good agreement and reflects the existence of an optimal point.

Table 4. Optimum conditions with model validation

\begin{tabular}{llll}
\hline A $\left(\right.$ Temperature, $\left.{ }^{\circ} \mathbf{C}\right)$ & \multirow{2}{*}{ B (Time, $(\min )$} & \multicolumn{2}{l}{ BET surface area $\left(\mathrm{g} / \mathbf{m}^{\mathbf{2}}\right)$} \\
\cline { 3 - 4 } & & Predicted & Experimental \\
\hline 764.46 & 77 & 717.6 & 720.0 \\
\hline
\end{tabular}

\section{Conclusion}

Oil palm empty fruit bunch (EFB) can be used as the perfect precursor with steam as the activating agent for the preparation of activated carbon with high BET surface area. Statistical optimization of BET surface area on the activated carbon production has been successfully performed using RSM via DOE software by conducting a CCD by varying the activation temperature and activation time. The optimum conditions for preparation high BET surface area activated carbon were obtained as follows; activation temperature $764.5^{\circ} \mathrm{C}$ and activation time $77 \mathrm{~min}$. Under these optimum conditions, the predicted value from the model of BET surface area is $717.6 \mathrm{~m}^{2} / \mathrm{g}$ and experimental values of BET surface area is $720.0 \mathrm{~m}^{2} / \mathrm{g}$ and this indicates the successful development model because small deviation error between of them.

\section{Acknowledgements}

This work was financially supported by the Research Management Institution (RMI) through Excellence Fund (600-RMI/DANA 5/3/RIF (311/2012)) and UiTM Shah Alam.

\section{References}

[1] S. Sumathi, S. Bhatia, K. T. Lee, and A. R. Mohamed, "Optimization of microporous palm shell activated carbon production for flue gas desulphurization: Experimental and statistical studies," Bioresource Technology, vol. 100, pp. 1614-1621, 2009.

[2] A. Arami-Niya, W. M. A. Wan Daud, F. S. Mjalli, F. Abnisa, and M. S. Shafeeyan, "Production of microporous palm shell based activated carbon for methane adsorption: Modeling and optimization using response surface methodology," Chemical Engineering Research and Design, vol. 90, pp. 776-784, 2012. 
[3] E. Kusrini, A. Seyopratiwi, and U. M. Yahya, "Preparation of Selenium-doped Activated Carbon and Its Utilization for Improving the Qualtiy of Used Coconut Oil," Journal of Physical Science vol. 18, pp. 11-21, 2007.

[4] O. Ioannidou and A. Zabaniotou, "Agricultural residues as precursors for activated carbon production-A review," Renewable and Sustainable Energy Reviews, vol. 11, pp. 1966-2005, 2007.

[5] W. Tongpoothorn, M. Sriuttha, P. Homchan, S. Chanthai, and C. Ruangviriyachai, "Preparation of activated carbon derived from Jatropha curcas fruit shell by simple thermo-chemical activation and characterization of their physico-chemical properties," Chemical Engineering Research and Design, vol. 89, pp. 335-340, 2011.

[6] Z. Q. Tan, J. Xiang, S. Su, H. C. Zeng, C. S. Zhou, L. S. Sun, $\mathrm{S}$. Hu, and J. R. Qiu, "Enhanced capture of elemental mercury by bamboo-based sorbents," Journal of hazardous materials, vol. 239, pp. 160-166, Nov 2012.

[7] A. Baçaoui, A. Yaacoubi, A. Dahbi, C. Bennouna, R. Phan Tan Luu, F. J. Maldonado-Hodar, J. Rivera-Utrilla, and C. Moreno-Castilla, "Optimization of conditions for the preparation of activated carbons from olive-waste cakes," Carbon, vol. 39, pp. 425-432, 2001.

[8] M. A. Jamaluddin, K. Ismail, M. A. Mohd Ishak, Z. Ab Ghani, M. F. Abdullah, M. T.-u. Safian, S. S. Idris, S. Tahiruddin, M. F. Mohammed Yunus, and N. I. N. Mohd Hakimi, "Microwave-assisted pyrolysis of palm kernel shell: Optimization using response surface methodology (RSM)," Renewable Energy, vol. 55, pp. 357-365, 2013.
[9] B. H. Hameed, I. A. W. Tan, and A. L. Ahmad, "Optimization of basic dye removal by oil palm fibre-based activated carbon using response surface methodology," Journal of hazardous materials, vol. 158, pp. 324-332, 2008.

[10] M. Asadullah, M. A. Rahman, A. Motin, and M. B. Sultan, "Adsorption Studies on Activated Carbon Derived from Steam Activation of Jute Stick Char," surface science and technology, vol. 23, pp. 73-80, 2007.

[11] T. Vitidsant, T. Suravattanasakul, and S. Damronglerd, "Production of Activated Carbon from Palm-oil Shell by Pyrolysis and Steam Activation in a Fixed Bed Reactor," ScienceAsia, vol. 25, pp. 211-222, 1999.

[12] Allwar, "Characteristics of micro- and mesoporous structure and surface chemistry of activated carbons produced by oil palm shell," presented at the International Conference on Chemical, Ecology and Environmental Science (ICEES'2012), Bangkok, 2012.

[13] S. A. Muyibi, N. Kamaldin, and J. Gombak, "Production Of activated carbon from oil palm empty fruit bunches for removal of zinc," presented at the Twelfth International Water Technology Conference, IWTC12, Alexandria, Egypt, 2008.

[14] M. K. B. Gratuito, T. Panyathanmaporn, R. A. Chumnanklang, N. Sirinuntawittaya, and A. Dutta, "Production of activated carbon from coconut shell: Optimization using response surface methodology," Bioresource Technology, vol. 99, pp. 4887-4895, 2008. 